\title{
INFLUENCE OF LIGHT REGIMES ON RESPIRATION, ACTIVITY OF ALTERNATIVE RESPIRATORY PATHWAY AND CARBOHYDRATES CONTENT IN MATURE LEAVES OF AJUGA REPTANS L.
}

\author{
NATALIA V. PYSTINA AND ROMAN A. DANILOV ${ }^{1 *}$
}

Department of Natural \& Environmental Sciences, Mid Sweden University, S-87188 Härnösand, Sweden

\begin{abstract}
Influence of different light regimes (plants grown in shade and in the sun) on respiration, activity of alternative respiratory pathway and carbohydrates content in mature leaves of Ajuga reptans L. was investigated. All experiments were carried out under natural conditions. Sun plants had higher respiration, activity of the alternative pathway and carbohydrates content compared to the shade plants. Additional experiments were performed in order to study effects of darkening as well as evolution of respiration and carbohydrates concentrations in leaves of $A$. reptans during the day. Darkening led to a decline in total respiration in all types of plants investigated. Activity of the alternative pathway remained unchanged by $20 \%$ in the leaves of the shade plants. On the other hand, darkness led to a twofold decrease in the activity of the alternative pathway in the leaves of the sun plants. Content of soluble carbohydrates in the darkness did not change in the leaves of the shade plants while significantly decreased in the leaves of the sun plants. Total respiration in the mature leaves of the shade plants studied did not change significantly during the day. However, a significant increase in the total respiration was detected in the mature leaves of the sun plants in the evening and in the night. Activity of the alternative respiratory pathway did not change significantly in the leaves of the shade plants during the day and corresponds to ca $20 \%$ of the total respiration. The sun plants examined exhibited significantly higher activity of the alternative pathway during the period of active photosynthesis. In general, activity of the alternative pathway varied in the sun plants between 30 and $35 \%$ of the total respiration during the day. Content of soluble carbohydrates decreased significantly during the day in the mature leaves of the shade plants, while no statistically significant changes by the sun plants could be detected. It has been suggested that increase in respiration and activity of the alternative pathway in the sun plants tested can be controlled by the content of carbohydrates in leaves. No clear proposal could be done concerning mechanisms regulating alternative pathway activity in the shade plants of $A$. reptans.
\end{abstract}

ADDITIONAL INDEX TERMS: alternative respiratory pathway, respiration, alternative oxidase, leaves, light, carbohydrates

Received: 16/9/2001 - Accepted: 30/11/2001

Department of Natural \& Environmental Sciences, Mid Sweden University, S-87188 Härnösand, Sweden

Tel: + 46 611-86292, Fax: + 46 611-86010

*corresponding author: E-mail: Roman.Danilov@tnv.mh.se 


\section{INTRODUCTION}

Both stress concept and stress adaptations in plants are a rapidly expanding research area. There are numerous stress factors the plants are confronted with in the nature. One of them is, of now doubt, the light (Hall and Rao, 1994). Respiration is one of the key processes in plants providing them with energy and metabolites. A general sensitivity of respiration to stress events is well known. Therefore, increase in respiration can often act as a sign of stress conditions to a plant because of the acclimatisation energetical costs (Larcher, 1995). Respiratory electron transport chain is located at the inner membrane of mitochondria. Two possible pathways of respiration in higher plants have been reported $-\mathrm{a}$ cytochrome pathway and an alternative pathway. The cytochrome pathway is the main source of ATP in plants, while the terminal cytochrome oxidase (COX) is the key enzyme of the electron transport chain. One of the striking features of the alternative oxidase (AOX), and, therefore, the alternative pathway, is its resistance to cyanide, while COX is completely depressed by cyanide. The alternative pathway is generally considered to be nonphosphorylating (Vanlerberghe and McIntosh, 1997).

The efficiency of respiration depends on the ratio of engagement of both respiratory pathways. The production of ATP declines and is less than that maximal possible if a part of the total respiration is being proceeded by the alternative (nonphosphorylating) pathway. However, the role of AOX and how spread AOX is in the nature remains unclear (e.g. Henry and Nyns 1975; Ordentlich et al., 1991; Day et al., 1995). Therefore, all new evidence dealing with functions and regulatory mechanisms of the alternative respiratory pathway are of a considerable interest.

Actual knowledge of the influence of light intensities on the ratio of engagement of the alternative respiratory pathway is more than scarce, although growth conditions are generally considered to be of a great importance for determination of the amount of AOX protein
(Vanlerberghe and McIntosh, 1997). Our aim was to investigate effects of different light intensities on the evolution of the alternative respiratory pathway activity in leaves of Ajuga reptans. A. reptans was chosen as the study object because it is a common shade-enduring habitant in European natural forest communities. We have investigated $A$. reptans from their northern areal. In this area $A$. reptans is one of the few postglacial relicts.

\section{MATERIAL AND METHODS}

A. reptans (Lamiaceae) were studied under natural conditions at $62^{\circ} 52^{\prime} \mathrm{N}$ near Syktyvkar, northeast Russia. Two principally different light regimes were applied: under the forest canopy (shade plants, $5 \%$ of the daylight) and on an open place (sun plants, $100 \%$ of the daylight), respectively.

Entirely mature (July) leaves of $A$. reptans were taken into consideration. The leaves were continuously sampled from 15 plants at 9.00 a.m. in order to avoid any possible artefacts caused by photosynthesis metabolites.

Small peaces $\left(0.0028 \mathrm{dm}^{2}\right)$ were cut off from the leaves sampled (three peaces per leave). The peaces were placed in a cuvette and the respiration was estimated by oxygen consumption $\left(\mu \mathrm{mol} \mathrm{O} \mathrm{g}^{-1} \mathrm{FW} \mathrm{h}{ }^{-1}\right)$ with the aid of an electrode of Clark-type at $20^{\circ} \mathrm{C}$. Activity and capacity of respiratory pathways were studied using method of specific inhibitors (Bahr and Bonner, 1973; Theologis and Laties, 1978). $25.0 \mathrm{mmol}$ benzhydroxamic acid (BHAM) and $5.0 \mathrm{mmol}$ $\mathrm{KCN}$ were used as inhibitors of AOX and COX, respectively. $0.5 \mathrm{mmol}$ 2,4-dinitrophenol (DNP) was used as uncoupler. The inhibitors were used both separately and together. All experiments were carried out in triplicate.

Additionally, evolution of respiration during the day in leaves of shade and sun $A$. reptans was studied in August. The measurements of respiration and determination of carbohydrates occurred each fourth hour. In order to test the influence of darkness on respiration and content of 
carbohydrates, leaves of both shade and sun plants were darkened ( $0 \%$ light) for $48 \mathrm{~h}$.

Activity of the alternative pathway $\left(\mathrm{v}_{\text {alt }}\right)$ was calculated as the difference between total respiration (in the absence of inhibitors) and respiration in the presence of $25.0 \mathrm{mmol}$ BHAM. Residual respiration $\left(\mathrm{V}_{\text {res }}\right)$ was measured in the presence of inhibitors of both the AOX and COX $(25.0$ mmol BHAM $+5.0 \mathrm{mmol} \mathrm{KCN})$. Activity of the cytochrome pathway $\left(\mathrm{v}_{\text {cyt }}\right)$ was calculated as the difference between respiration in the presence of the 25.0 mmol BHAM and residual oxygen uptake. Capacity of the alternative pathway $\left(\mathrm{V}_{\text {alt }}\right)$ was calculated as the difference between respiration in the presence of $5.0 \mathrm{mmol} \mathrm{KCN}$ and residual respiration. Capacity of the cytochrome pathway $\left(\mathrm{V}_{\text {cyt }}\right)$ was calculated as the difference between respiration in the presence of the 25.0 mmol BHAM $+0.5 \mathrm{mmol} 2,4-\mathrm{DNP}$ and residual oxygen uptake. The engagement of respiratory pathways $\left(\mathrm{p}_{\mathrm{alt}}\right.$ and $\left.\mathrm{p}_{\mathrm{cyt}}\right)$ was estimated as relation between respective activity and capacity.

Content of soluble carbohydrates was measured according to Sweely et al. (1963). The results were expressed as $\mathrm{mg} \mathrm{g}^{-1} \mathrm{FW}$.

Statistical analyses were performed in the computer package Minitab 13.0.

\section{RESULTS AND DISCUSSION}

Total respiration of the sun plants was two times higher than that of the shade plants (Table 1). The respiration in the leaves of the sun plants was more sensitive to the BHAM than in the leaves of the shade plants. Cyanide caused a significant decline in respiration in the leaves of the sun plants while not having any inhibitory effects in the shade plants. Residual respiration (measured in the presence of BHAM and cyanide) was considerably higher in the leaves of the sun plants. The use of the uncoupler stimulated the respiration in the shade plants by $54 \%$ and did not significantly affect that in the sun plants.

Activity of the alternative pathway was two times higher in the mature leaves of the sun plants compared to the shade plants studied (Table 2 ). However, capacity of the alternative pathway was lower in the mature leaves of the sun plants compared to the shade plants. The alternative pathway was near saturation entirely in the mature leaves of the sun plants. Both the activity and the capacity of the cytochrome pathway were considerably lower in the mature leaves of the sun plants compared to those of the shade plants.

Content of soluble carbohydrates in the mature leaves of the sun plants studied exceeded by nearby threefold that in the mature leaves of the shade plants (Table 3). Low quantities of starch were detected in the mature leaves of both sun plants $\left(0.12 \mathrm{mg} \mathrm{g}^{-1} \mathrm{FW}\right)$ and shade plants $(0.06 \mathrm{mg}$ $\left.\mathrm{g}^{-1} \mathrm{FW}\right)$.

TABLE 1. Influence of inhibitors on respiration $\left(\mu \mathrm{mol} \mathrm{O} \mathrm{g}^{-1} \mathrm{FW} \mathrm{h}^{-1}\right.$ ) in mature leaves of $A$. reptans growing under different light conditions. *- the difference is statistically significant $(\mathrm{P} \leq 0.05)$ compared to the control. The values of SE are shown.

\begin{tabular}{lcc}
\hline Inhibitors & Shade plants & Sun plants \\
\hline Control & $8.7 \pm 0.5$ & $18.3 \pm 0.9$ \\
25.0 mmol BHAM & $7.1 \pm 0.4^{*}$ & $11.6 \pm 0.9^{*}$ \\
5.0 mmol KCN & $9.2 \pm 0.3$ & $13.3 \pm 2.3^{*}$ \\
25.0 mmol BHAM + & $1.6 \pm 0.1^{*}$ & $5.1 \pm 0.2^{*}$ \\
5.0 mmol KCN & & \\
0.5 mmol 2,4-DNP & $13.4 \pm 0.4^{*}$ & $16.4 \pm 0.9$ \\
0.5 mmol 2,4-DNP + & $12.5 \pm 0.1^{*}$ & $14.8 \pm 0.4^{*}$ \\
25.0 mmol BHAM & & \\
\hline
\end{tabular}

Total respiration in the mature leaves of the shade plants studied did not change significantly during the day (Figure 1). However, a significant increase in the total respiration was 
TABLE 2. Parameters characterising respiratory pathways in mature leaves of $A$. reptans growing under different light conditions. AP - alternative pathway, $\mathrm{CP}$ - cytochrome pathway (percentages of the control). The values of SE are shown.

\begin{tabular}{lcc}
\hline Parameters & Shade plants & Sun plants \\
\hline Activity of AP $\left(\mathrm{v}_{\text {alt }}\right)$ & $18 \pm 3$ & $36 \pm 1$ \\
Capacity of AP $\left(\mathrm{V}_{\text {alt }}\right)$ & $88 \pm 4$ & $45 \pm 2$ \\
$\begin{array}{l}\text { Engagement of AP } \\
\left(p_{\text {alt }}\right)\end{array}$ & 0.2 & 0.8 \\
Activity of CP $\left(\mathrm{v}_{\text {cyt }}\right)$ & $64 \pm 2$ & $36 \pm 1$ \\
Capacity of CP $\left(\mathrm{V}_{\text {cyt }}\right)$ & $126 \pm 5$ & $53 \pm 3$ \\
Engagement of CP & 0.5 & 0.7 \\
$\left(p_{\text {cyt }}\right)$ & & \\
Residual respiration & $18 \pm 1$ & $28 \pm 1$ \\
$\left(\mathrm{v}_{\text {res }}\right)$ &
\end{tabular}

detected in the mature leaves of the sun plants in the evening and in the night. Respiration in the presence of $25 \mathrm{mmol}$ BHAM changed in accordance with the total respiration by the shade plants as well as by the sun plants. Activity of the alternative respiratory pathway did not change significantly in the leaves of the shade plants during the day and corresponds to ca $20 \%$ of the total respiration (Table 4). The sun plants examined exhibited significantly higher activity of the alternative pathway during the period of active photosynthesis. In general, activity of the alternative pathway varied in the sun plants between 30 and $35 \%$ of the total respiration during the day. Content of soluble carbohydrates decreased significantly in the mature leaves of the shade plants, while no statistically significant changes by the sun plants could be detected (Tables 5 and 6).

TABLE 3. Content of soluble carbohydrates (mg $\mathrm{g}^{-1} \mathrm{FW}$ ) in mature leaves of $A$. reptans growing under different light conditions. The values of SE are shown.

\begin{tabular}{lcc}
\hline Carbohydrates & Shade plants & Sun plants \\
\hline Monosaccharides & $4.3 \pm 0.3$ & $16.1 \pm 3.0$ \\
Disaccharides & $3.4 \pm 0.5$ & $11.4 \pm 2.0$ \\
Oligosaccharides & $0.3 \pm 0.1$ & $2.5 \pm 0.6$ \\
$\begin{array}{l}\text { Total amount of } \\
\text { carbohydrates }\end{array}$ & $8.0 \pm 0.3$ & $30.0 \pm 5.3$ \\
\end{tabular}

TABLE 4. Evolution of the activity $\left(\mathrm{mmol} \mathrm{O}_{2} \mathrm{~g}^{-1}\right.$ $\mathrm{FW} \mathrm{h}^{-1}$ ) of the alternative respiratory pathway in the mature leaves of $A$. reptans during the day. The values of $\mathrm{SE}$ are shown.

\begin{tabular}{ccc}
\hline Daytime, $h$ & Shade plants & Sun plants \\
\hline 12 & $2.1 \pm 0.3$ & $6.1 \pm 0.8$ \\
18 & $2.1 \pm 0.8$ & $7.1 \pm 0.4$ \\
24 & $2.2 \pm 0.4$ & $5.9 \pm 0.7$ \\
6 & $1.8 \pm 0.4$ & $4.6 \pm 0.5$ \\
\hline
\end{tabular}


TABLE 5. Evolution of soluble carbohydrates content ( $\left.\mathrm{mg} \mathrm{g}^{-1} \mathrm{FW}\right)$ in mature leaves of the shade plants of $A$. reptans during the day. The values of SE are shown.

\begin{tabular}{lcccc}
\hline Daytime, h & 12 & 18 & 24 & 6 \\
\hline Monosaccharides & $12.5 \pm 0.2$ & $11.1 \pm 0.1$ & $6.2 \pm 0.1$ & $8.3 \pm 0.3$ \\
Disaccharides & $11.0 \pm 0.1$ & $10.9 \pm 0.4$ & $10.2 \pm 0.7$ & $10.1 \pm 0.8$ \\
Oligosaccharides & $2.7 \pm 0.3$ & $0.9 \pm 0.1$ & $1.5 \pm 0.2$ & $1.0 \pm 0.1$ \\
& & & & \\
Total amount of & $26.2 \pm 0.2$ & $22.9 \pm 0.6$ & $17.9 \pm 0.9$ & $19.4 \pm 0.1$ \\
carbohydrates & & & & \\
\end{tabular}

TABLE 6. Evolution of soluble carbohydrates content $\left(\mathrm{mg} \mathrm{g}^{-1} \mathrm{FW}\right)$ in mature leaves of the sun plants of A. reptans during the day. The values of SE are shown.

\begin{tabular}{lcccc}
\hline Daytime, h & 12 & 18 & 24 & 6 \\
\hline Monosaccharides & $10.6 \pm 0.2$ & $13.4 \pm 0.1$ & $11.7 \pm 0.3$ & $11.2 \pm 1.0$ \\
Disaccharides & $15.2 \pm 0.8$ & $18.3 \pm 0.2$ & $13.4 \pm 0.4$ & $15.8 \pm 0.4$ \\
Oligosaccharides & $7.1 \pm 0.4$ & $3.0 \pm 0.2$ & $5.4 \pm 0.3$ & $7.1 \pm 0.4$ \\
& & & & \\
$\begin{array}{l}\text { Total amount of } \\
\text { carbohydrates }\end{array}$ & $32.9 \pm 1.3$ & $34.7 \pm 0.5$ & $30.5 \pm 0.4$ & $34.1 \pm 1.0$
\end{tabular}


Darkening led to a decline in total respiration in all types of plants investigated. Activity of the alternative pathway remained unchanged by $20 \%$ in the leaves of the shade plants. On the other hand, a twofold decrease in the activity of the alternative pathway was detected in the leaves of the sun plants (Figure 2). Content of soluble carbohydrates did not change in the leaves of the shade plants while significantly decreased in the leaves of the sun plants.
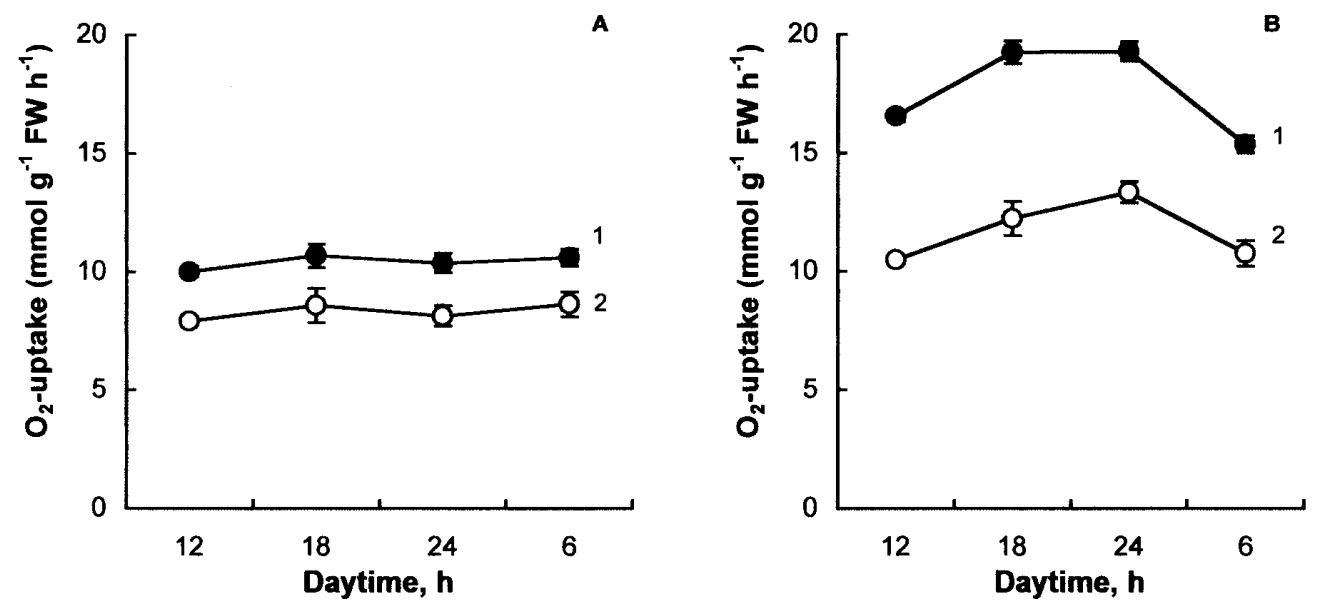

FIGURE 1. Evolution of respiration in mature leaves of $A$. reptans during the day. A - shade plants, $\mathrm{B}-$ sun plants, 1 - total respiration (no inhibitors), 2 - respiration in the presence of 25 mmol BHAM. The values of SE are shown.
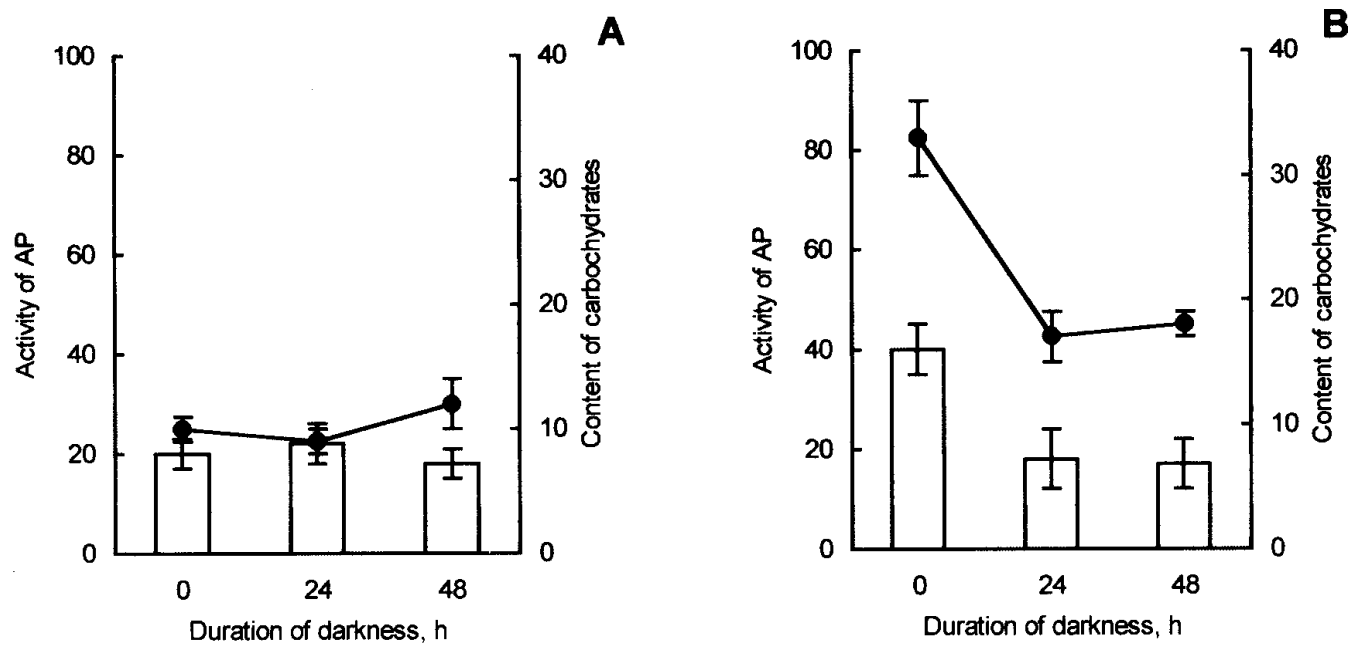

FIGURE 2. Influence of darkening ( $0 \%$ of light) on the activity of the alternative respiratory pathway (AP, $\%$ of the total respiration, bars) and carbohydrates content ( $\mathrm{mg} \mathrm{g}^{-1} \mathrm{FW}$, lines) in leaves of $A$. reptans. $\mathrm{A}$ - shade plants, $\mathrm{B}$ - sun plants. 
Our results indicate that light conditions can have profound effects on the activity of the alternative respiratory pathway in mature leaves of A. reptans. The fact that total respiration can be broadly affected by quality and quantity of light is well known. Light determines activity of photosynthesis and amount of carbohydrates in leaves (Larcher, 1995). However, the question to which extent the alternative respiratory pathway can be influenced by different light regimes is actually under debate (e.g. Millenaar et al., 2000). In the present study, respiration, activity of the alternative pathway and content of soluble carbohydrates clearly increased in the leaves of sun plants compared to those growing in shade. We believe that this phenomenon could be explained by a positive correlation between activity of the alternative pathway and concentrations of sugars in leaves. According to the "overflow concept" suggested by Lambers (1982), the alternative pathway can regulate concentrations of sugars in tissues while the cytochrome pathway is saturated or restricted.

As shown by Atkins et al. (1993), leaves of light-grown plants of Belgium endive had higher capacity of the alternative pathway and higher content of carbohydrates than in dark-grown plants. However, no differences in activity of the alternative pathway were detected between the light- and dark-grown plants. Our results indicate that activity of the alternative pathway was significantly higher in the sun plants compared to those grown in shade. Noguchi et al. (2001) also showed that leaves of shade species had lower activity of the alternative pathway than in leaves of sun plants. On the other hand, the shade plants of $A$. reptans had higher capacity of the alternative pathway than the sun plants. We believe that high capacity in leaves of the shade plants can be considered as an evidence of a high respiratory potential.

The results obtained in the present study showed no significant changes in the activity of the alternative pathway in the leaves of the sun and shade plants during the day. However, a clear decline in the content of carbohydrates in the shade plants and no significant fluctuations in the content of carbohydrates in the sun plants were detected. We believe that increase in respiration and activity of the alternative pathway in the sun plants tested depends on the content of carbohydrates in leaves. The trends observed in the darkening experiments can be considered as a good supporting evidence for this suggestion. On the other hand, it is not clear which mechanisms acted in regulation of the alternative pathway activity in the shade plants. No agreement has been achieved about general mechanisms regulating AOX activity, either (Vanlerberghe and McIntosh, 1997).

In summary, changes in light intensities affected concentrations of sugars in the mature leaves of $A$. reptans. The increase in the content of carbohydrates led to activation of the alternative pathway.

\section{REFERENCES}

ATKIN, O. K.; CUMMINS, W. R. AND COLLIER D. E. Light induction of alternative pathway capacity in leaf slices of Belgium endive. Plant Cell Environ., 16: 231-235, 1993.

BAHR, J. T. AND BONNER, W. D. JR. Cyanideinsensitive respiration. J. Biol. Chem., 248: 3441-3450, 1973.

DAY, D. A.; WHELAN, J.; MILLAR, A. H.; SIEDOW, J. N. AND WISKICH, J. T. Regulation of alternative oxidase in plants and fungi. Aust. J. Plant Physiol., 22: 497-509, 1995.

HALL, D. O. AND RAO, K. K. Photosynthesis. $5^{\text {th }}$ edition, Cambridge University Press, Cambridge, 1994.

HENRY, M. F. AND NYNS E.J. Cyanideinsensitive respiratory: an alternative mitochondrial pathway. Sub-Cell. Biochem., 4: 5-65, 1975.

LAMBERS, H. Cyanide-resistant respiration: a non-phosphorylating electron transport pathway acting as an energy overflow. Physiol. Plant., 55: 478-485, 1982. 
LARCHER, W. Physiological Plant Ecology. Springer Verlag, Berlin, 1995.

MILLENAAR, F. F.; ROELOFS, R.; GONZALEZ-MELER, M. A.; SIEDOW, J. N.; WAGNER, A. M. AND LAMBERS, H. The alternative oxidase in roots of Poa annua after transfer from high-light to low-light conditions. Plant Journal, 23: 623-632, 2000.

NOGUCHI, K.; GO, C. S.; TERASHIMA, I.; UEDA, S. AND YOSHIMARI, T. Activities of the cyanide-resistant respiratory pathway in leaves of sun and shade species. Aust. J. Plant Physiol., 28: 27-35, 2001.

ORDENTLICH, A.; LINZER, R. AND RASKIN, I. Alternative respiration and heat evolution in plants. Plant Physiol., 97: 1545-1550, 1991.
SWEELY, C. C.; BENTLEY, R.; MAKITA, M. AND WELLS, W. W. Gas-liquid chromatography of trimethylsilyl derivatives of sugars and related substances. J. Am. Chem. Soc., 85: 2497-2507, 1963.

THEOLOGIS, A. AND LATIES, G.G. Relative contribution of cytochrome mediated and cyanide-resistant electron transport in fresh and aged potato slices. Plant Physiol., 62: 232237, 1978.

VANLERBERGHE, G.G. AND MCINTOSH, L. Alternative oxidase: from gene to function. Annu. Rev. Plant Physiol. Plant Mol. Biol., 48: 703-734, 1997. 